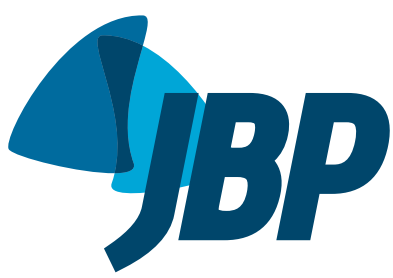

\title{
Tracheal lobular capillary hemangioma treated with laser photocoagulation
}

\author{
Hans Dabó1, Rita Gomes², Nelson Teixeira1, Gilberto Teixeira³ \\ Gabriela Fernandes ${ }^{1}$, Adriana Magalhães ${ }^{1}$
}

\section{TO THE EDITOR:}

Primary tumors of the trachea are rare, with an estimated annual incidence of 2.7 new cases per million population. ${ }^{(1)}$ These tumors are approximately 180 times less common than are lung tumors, ${ }^{(2)}$ accounting for $0.1-0.3 \%$ of all tumors. ${ }^{(2,3)}$ Their diagnosis is usually delayed, because the symptoms are initially misinterpreted or patients are misdiagnosed as having asthma.

Lobular capillary hemangioma ( $\mathrm{LCH})$, also known as pyogenic granuloma, is a benign vascular tumor most commonly affecting the skin or mucous membranes (oral and nasal). It is extremely rare among all primary tracheal tumors, and there are only few case reports in the literature. ${ }^{(1)}$ Here, we present the case of a rare benign tracheal tumor presenting with recurrent hemoptysis, which was diagnosed by and treated with bronchoscopic techniques.

A 51-year-old female with a 6-month history of recurrent hemoptysis was admitted to the hospital after a significant episode of hemoptysis. She had no other symptoms (i.e., no sputum production, dyspnea, chest pain, weight loss, excessive sweating, or fever). She had a history of papillary thyroid carcinoma, having been submitted to total thyroidectomy and adjuvant therapy with radioactive iodine 16 years prior, with no evidence of relapse to date. Since then, she was on a replacement treatment regimen with levothyroxine sodium. She described herself as a nonsmoker and denied any relevant exposure to tobacco smoke. The physical examination was unremarkable. Routine laboratory tests revealed no abnormalities. A chest X-ray was normal. A chest CT scan with contrast enhancement revealed a newly forming lesion in the left lateral wall of the trachea (Figure $1 \mathrm{~A}$ ), with no other significant changes. Flexible bronchoscopy was performed, confirming the presence of a purple polypoid bleeding lesion in the left lateral wall of the lower third of the trachea, without any additional findings. In order to better control the bleeding, rigid bronchoscopy was performed, with an $8.5 \mathrm{~mm}$ bronchoscope (Karl Storz Instruments, Tuttlingen, Germany). The lesion was removed en bloc with rigid forceps, resulting in significant hemorrhage, which required local instillation of cold saline and epinephrine $(1: 10,000)$; however, bleeding control failed. Hemostasis was then achieved using laser photocoagulation (Multidiode Endolaser 30; INTERmedic Arfran S.A., Barcelona, Spain; Figure 1B). After the procedure, no additional complications resulting from the treatment were noted. The histopathology of the tumor revealed $\mathrm{LCH}$, with no signs of malignancy (Figure 2).

Tracheal tumors are rare, and there is no clear explanation for that. Some authors suggest that the turbulent flow in the trachea might protect the mucosa, preventing the deposit of inhaled carcinogens. ${ }^{(2)}$

Tracheal LCH is a benign vascular tumor and is exceedingly rare. Typically, this tumor presents as a painless bleeding mass adhered to mucosal or cutaneous surfaces of the upper respiratory tract, most commonly affecting the lip, nose, oral cavity, or tongue. ${ }^{(4)}$ Histologically, it has a distinctive lobular arrangement of capillaries in an edematous fibroblastic stroma, and the surface is occasionally ulcerated. ${ }^{(1,5)}$

Although the pathogenesis of $\mathrm{LCH}$ is unclear, various factors have been implicated, such as hormonal influence, certain drugs, viral oncogenes, Bartonella sp. infection, production of angiogenic factors, and cytogenetic clonal deletion abnormalities, ${ }^{(4,6)}$ There have been no reports that levothyroxine sodium is among the offending drugs. Traumatic lesions have also been implicated, although only in a minority of the cases. ${ }^{(1,4,6)}$ In the case reported here, there was a history of endotracheal intubation 16 years prior, due to the thyroid surgery, and that might have been a contributing risk factor.

Cough and hemoptysis are the most common symptoms of tracheal $\mathrm{LCH}_{,}(1,5,7)$ the latter ranging from minor to massive. ${ }^{(8)}$ Our patient presented with a 6-month history of recurrent hemoptysis.

For cutaneous LCH, various effective treatment modalities have been reported, including excision, curettage, electrodessication, chemical cauterization, and laser surgery. Mucosal LCH has been treated with snare cautery, excision biopsy, and plaque radiation. The preferred treatment for LCH of the trachea or bronchus in adults has yet to be established because of the limited number of cases $^{(9)}$; in general, it depends on the extent or size of the lesion, age of the patient, comorbidities, and other factors contributing to the overall clinical picture. ${ }^{(4)}$ At early detection, $\mathrm{LCH}$ is small and can be treated endoscopically with low morbidity. ${ }^{(7)}$ Due to the pathological characteristics of these lesions, bleeding is a common complication during the removal process, and hemostasis is difficult to achieve. Despite this, in most of the reported cases, flexible bronchoscopy produced favorable responses. However, if the risk of bleeding is high, the use of rigid bronchoscopy during the removal process should be considered.(4) In our patient, rigid 

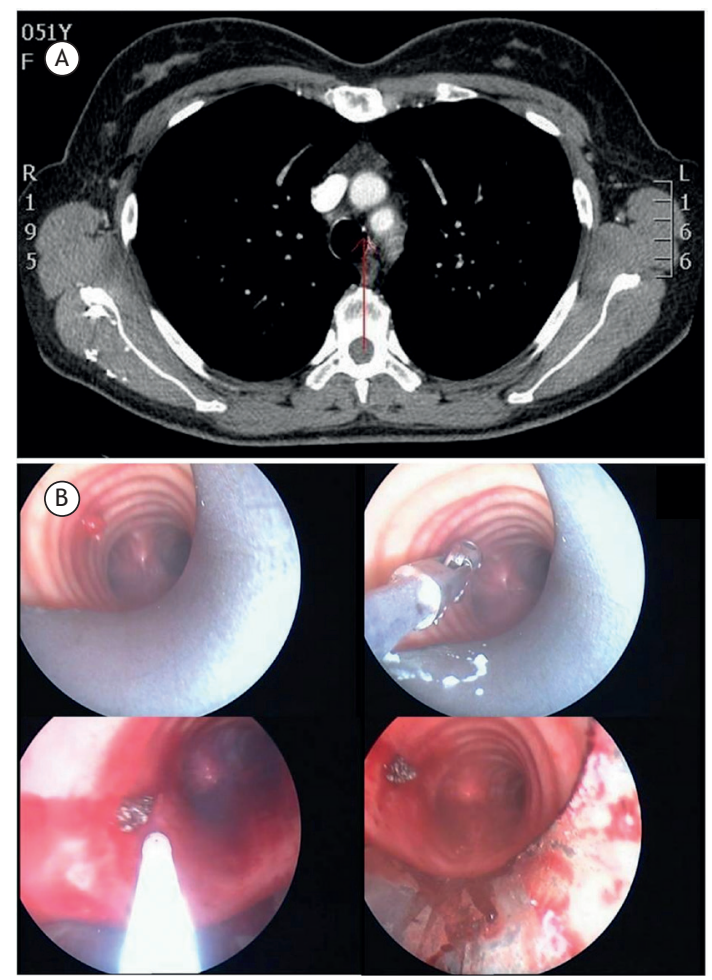

Figure 1. In A, a chest CT scan with contrast enhancement showing a small lesion in the left lateral wall of the trachea (red arrow). In B, bronchoscopic images confirming the presence of a purple polypoid lesion in the left lateral wall of the lower third of the trachea; removal of the lesion (with forceps) resulted in significant hemorrhage, which was controlled with laser photocoagulation.

bronchoscopy with laser photocoagulation was the procedure of choice in order to achieve better control

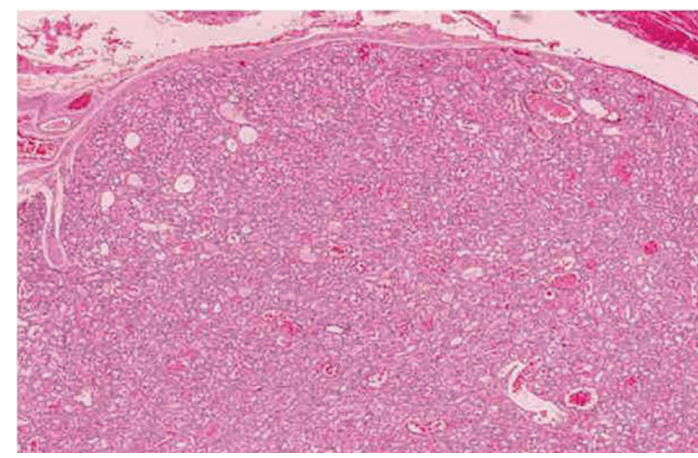

Figure 2. Histological examination of the lesion revealed numerous small vessels, some of which were capillaries, arranged in a lobular pattern and separated by a fibrous stroma with accompanying acute inflammatory changes, thus confirming the diagnosis of lobular capillary hemangioma. There were no signs of malignancy (H\&E staining; magnification $\times 100$ ).

of the bleeding. In a previous report, hemorrhage during tracheal LCH removal was successfully treated with laser therapy. ${ }^{(10)}$

The recurrence of skin and mucosal LCH after local therapy is a well-known concern. Although there is no formal recommendation other than clinical re-evaluation, it might be necessary to use bronchoscopy during the follow-up period, because there is a risk of local recurrence. ${ }^{(1)}$

During the follow-up period, our patient had no recurrence of hemoptysis. At 27 months after the treatment, flexible bronchoscopy showed no signs of relapse. Although exceedingly rare, $\mathrm{LCH}$ of the trachea or bronchus should be considered as a cause of recurrent hemoptysis, especially in patients with normal radiological findings.

\section{REFERENCES}

1. Prakash S, Bihari S, Wiersema U. A rare case of rapidly enlarging tracheal lobular capillary hemangioma presenting as difficult to ventilate acute asthma during pregnancy. BMC Pulm Med. 2014;14:41. http://dx.doi.org/10.1186/1471-2466-14-41

2. Caiado A, Moura e Sá J. Tracheal tumors review--a clinical case of adenoid cystic carcinoma [Article in Portuguese]. Rev Port Pneumol. 2008;14(4):527-34. http://dx.doi.org/10.1016/S0873-2159(15)302579

3. Hoerbelt R, Padberg W. Primary tracheal tumors of the neck and mediastinum : resection and reconstruction procedures [Article in German]. Chirurg. 2011;82(2):125-33. http://dx.doi.org/10.1007/ s00104-010-1974-7

4. Amy FT, Enrique DG. Lobular capillary hemangioma in the posterior trachea: a rare cause of hemoptysis. Case Rep Pulmonol. 2012;2012:592524.

5. Irani S, Brack T, Pfaltz M, Russi EW. Tracheal lobular capillary hemangioma: a rare cause of recurrent hemoptysis. Chest. 2003;123(6):2148-9. http://dx.doi.org/10.1378/chest.123.6.2148
6. Lawley LP. Pyogenic granuloma (Lobular capillary hemangioma). In: Levy ML, Corona R, editors. UpToDate. Waltham (MA): UpToDate; 2015. Available from: http://www.uptodate.com/home/index.html

7. Porfyridis I, Zisis C, Glinos K, Stavrakaki K, Rontogianni D, Zakynthinos $S$, et al. Recurrent cough and hemoptysis associated with tracheal capillary hemangioma in an adolescent boy: a case report. J Thorac Cardiovasc Surg. 2007;134(5):1366-7. http://dx.doi.org/10.1016/j. jtcvs.2007.07.014

8. Ahn Y, Chang H, Lim YS, Hah JH, Kwon TK, Sung MW, et al. Primary tracheal tumors: review of 37 cases. J Thorac Oncol. 2009;4(5):6358. http://dx.doi.org/10.1097/JTO.0b013e31819d18f9

9. Cho NJ, Baek AR, Kim J, Park JS, Jang AS, Park JS, et al. A case of capillary hemangioma of lingular segmental bronchus in adult. Tuberc Respir Dis (Seoul). 2013;75(1):36-9. http://dx.doi.org/10.4046/ trd.2013.75.1.36

10. Strausz J, Soltész I. Bronchial capillary hemangioma in adults. Pathol Oncol Res. 1999;5(3):233-4. http://dx.doi.org/10.1053/ paor.1999.0194 